\title{
Des aérosols multicolores
}

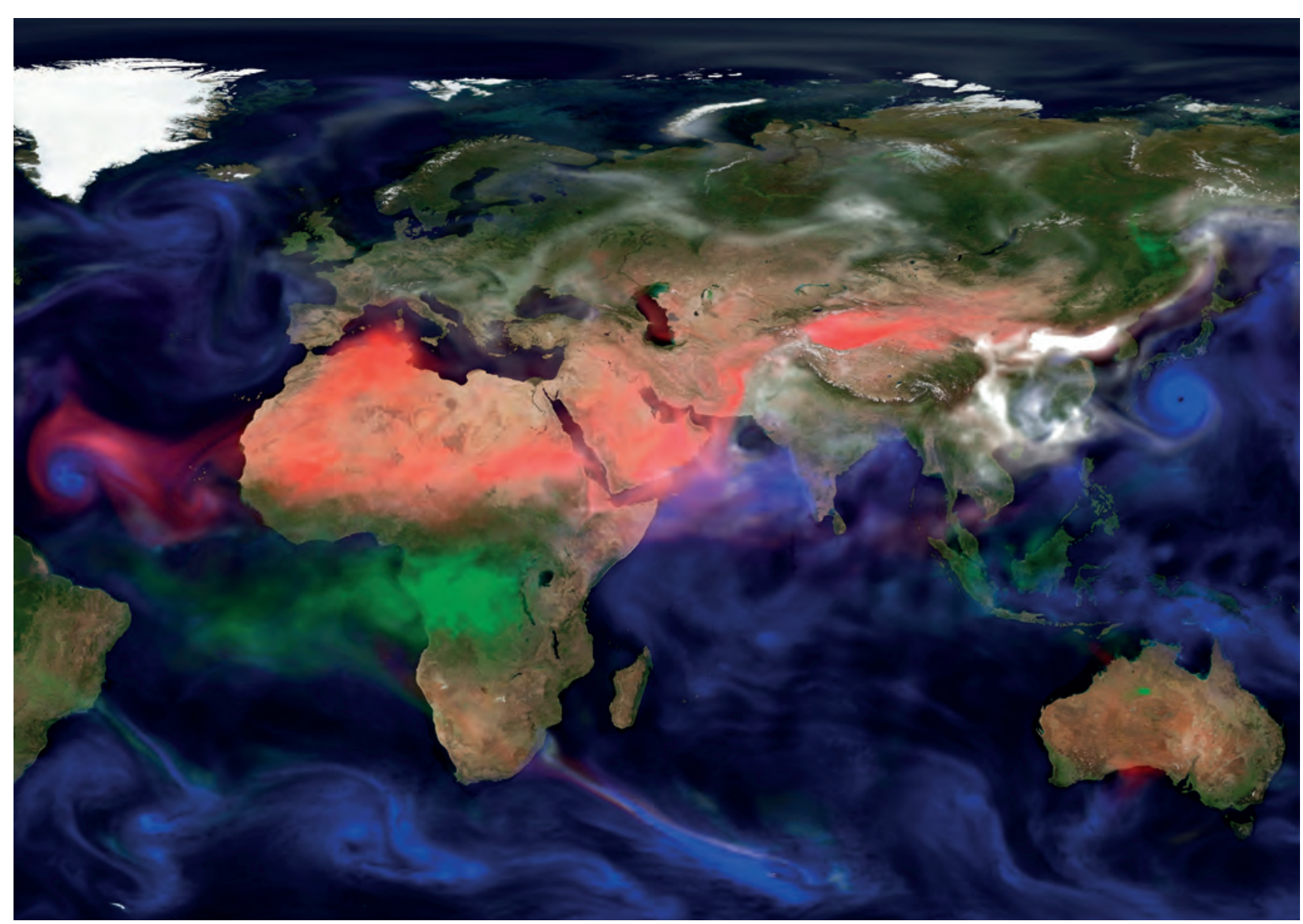

Crédit : graphique (Simone Mantovani, MEEO, Ferrara, Italie, http://www.meeo.it/), données (Angela Benedetti, projet MACC II, http://www.copernicus-atmosphere.eu/)

Les aérosols sont de petites particules en suspension dans l'atmosphère dont les sources sont multiples. Leur durée de vie dans l'atmosphère est d'environ une semaine. Nous pouvons observer les aérosols à partir de l'espace et disposons aussi de modèles qui permettent de prédire leur évolution.

Le Centre européen pour les prévisions météorologiques à moyen-terme (CEPMMT), aidé en cela par des partenaires académiques et institutionnels, opère désormais une surveillance et une prévision quasi opérationnelle des aérosols atmosphériques. Celle-ci s'appuie sur une technique d'assimilation de données qui combine au mieux les distributions observées par l'instrument Modis et simulées par le modèle IFS. Le document illustre pour la journée du $1^{\text {er }}$ septembre 2009 sur une partie du globe combien la distribution des aérosols dépend des phénomènes météorologiques. On a représenté les aérosols marins (en bleu, produits essentiellement par la friction du vent sur la surface de l'océan), les poussières désertiques (en rouge, émises par la friction du vent sur la surface des régions arides et semi-arides), les aérosols qui viennent des feux de végétation (en vert) et enfin les aérosols émis dans les régions industrialisées (en blanc). 

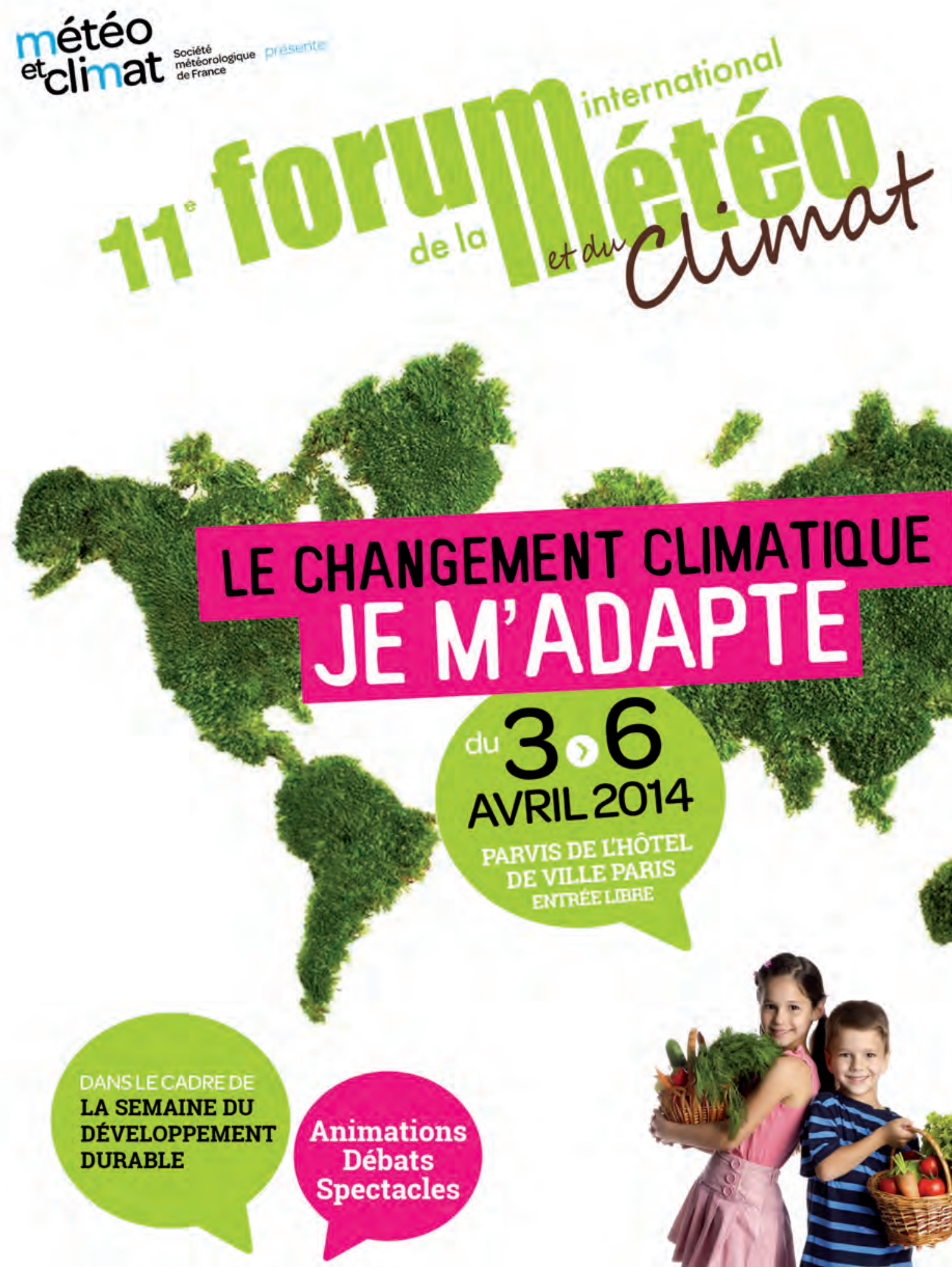

www.forumeteoclimat.com
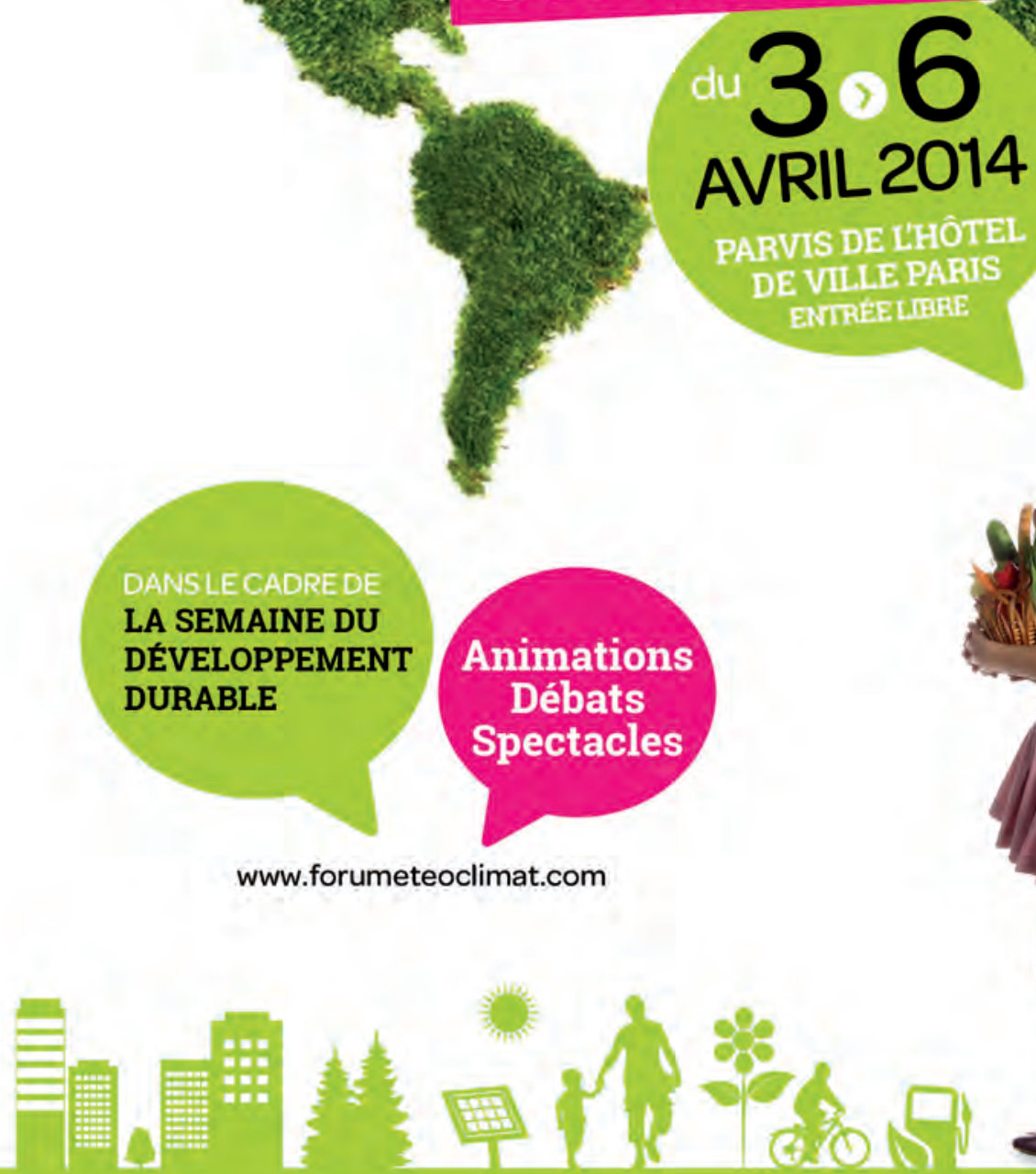

DARUS DE THOTII

DE VILLE PARIS

ENTREELTRE

Sous le patronage de

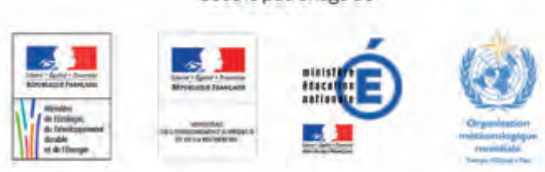

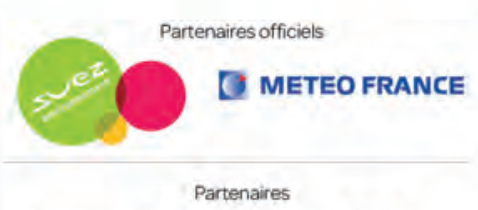

Hébergeur officie
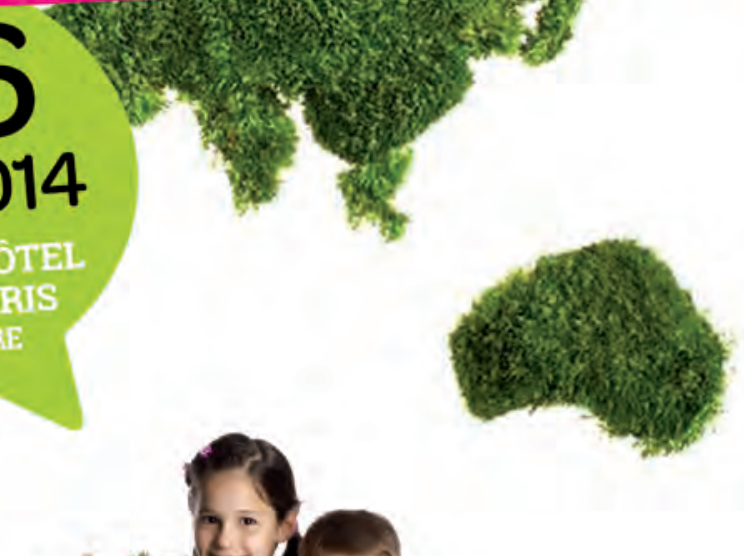